\title{
Carfilzomib is an effective anticancer agent in anaplastic thyroid cancer
}

\author{
Amit Mehta, ${ }^{1,2}$, Lisa Zhang', Myriem Boufraqech', Yaqin Zhang ${ }^{3}$, Dhaval Patel', \\ Min Shen ${ }^{3}$ and Electron Kebebew ${ }^{1}$ \\ ${ }^{1}$ Endocrine Oncology Branch, National Cancer Institute, National Institutes of Health, Bethesda, \\ Maryland 20892, USA \\ ${ }^{2}$ Geisel School of Medicine at Dartmouth, Hanover, New Hampshire 03755, USA \\ ${ }^{3}$ National Institutes of Health, National Center for Advancing Translational Sciences, Bethesda, Maryland, USA
}

Correspondence

should be addressed

to E Kebebew

Email

kebebewe@mail.nih.gov

\begin{abstract}
Anaplastic thyroid cancer (ATC) is one of the most aggressive human malignancies. Currently, there is no standard or effective therapy for ATC. Drug repurposing for cancer treatment is an emerging approach for identifying compounds that may have antineoplastic effects. The aim of this study was to use high-throughput drug library screening to identify and subsequently validate novel therapeutic agents with anticancer effects in ATC. We performed quantitative high-throughput screening (qHTS) in ATC cell lines (SW-1736, 8505C, and C-643), using a compound library of 3282 drugs. qHTS identified 100 compounds that were active in all three ATC cell lines. Proteasome inhibitors were one of the most active drug categories according to enrichment analysis. Of the three proteasome inhibitors screened, a second-generation proteasome inhibitor, carfilzomib, was the most active. Treatment of ATC cells with carfilzomib significantly inhibited cellular proliferation and induced G2/M cell cycle arrest and caspase-dependent apoptosis. Mechanistically, carfilzomib increased expression of p27 (CDKN1B) and decreased expression of the anti-apoptotic protein ATF4. Pretreatment with carfilzomib reduced in vivo metastases (lung, bone, liver, and kidney) and disease progression, and decreased $\mathrm{N}$-cadherin expression. Carfilzomib treatment of mice with established, widely metastatic disease significantly increased their survival, without significant toxicity. Our findings support the use or clinical study of carfilzomib as a therapeutic option in patients with advanced and metastatic ATC.
\end{abstract}

\section{Introduction}

Thyroid cancer is the most common endocrine malignancy (Howlader et al. 2013). Anaplastic thyroid cancer (ATC) accounts for $1-2 \%$ of all thyroid cancers, but is the most common cause of thyroid-cancer-related deaths (Kebebew et al. 2005, Nagaiah et al. 2011). Patients with ATC present with advanced disease with local invasion and metastasis (90\% of all cases), and even when the disease is localized (10\% of all cases), recurrence and metastatic disease develop in most patients even after complete initial tumor resection. ATC is one of the most aggressive human cancers and has a median survival of only 5 months, and fewer than $20 \%$ of patients with ATC survive longer than 1 year. Current treatment regimens fail to provide durable, long-term clinical benefits (Kebebew et al. 2005, Granata et al. 2013), and so there is a major need to develop new, effective treatments.

Development of new therapies for rare cancers such as ATC has been hindered for several reasons. Traditional

Published by Bioscientifica Ltd 
approaches to drug discovery require an often-prohibitive investment of time and funding, which is an issue that is even more significant for orphan cancers. The drug development process is also further restricted by the decreasing number of compounds entering development phases, as well as the high rate of late-stage drug failures (Munos 2009). A new and inventive approach to cancer therapy development is to exploit the multitude of already established compounds approved for clinical use for other indications (Shahinas et al. 2010, Shum et al. 2010, Miller et al. 2014). Recycling established agents for new indications has proven a far more attractive approach, especially for rare cancers such as ATC. Given that these compounds have known pharmacokinetic, pharmacodynamic, and toxicity profiles, promising drugs can be rapidly transitioned into phase II or III clinical trials to test for efficacy.

In this study, we completed a quantitative highthroughput screening (qHTS) of 3282 clinically approved drugs in ATC cell lines. Active agents were filtered based on both enrichment and pharmacokinetic analyses. We found the proteasome inhibitor drug category to be one of the most active categories, and validated the anticancer activity of carfilzomib in both in vitro and in vivo studies.

\section{Materials and methods}

\section{Cell lines}

Human ATC cell lines 8505C (European Collection of Cell Cultures, Salisbury, UK), C-643 (CLS Cell Lines Service GmbH, Eppelheim, Germany), and SW-1736 (CLS Cell Lines Service $\mathrm{GmbH}$ ) were maintained in DMEM supplemented with $10 \%$ FCS, penicillin $(100 \mathrm{U} / \mathrm{ml})$, streptomycin $(100 \mu \mathrm{g} / \mathrm{ml})$, fungizone $(250 \mathrm{ng} / \mathrm{ml})$, and insulin $(10 \mu \mathrm{g} / \mathrm{ml})$ in a $5 \% \mathrm{CO}_{2}$ atmosphere at $37^{\circ} \mathrm{C}$. The $8505 \mathrm{C}$ cell line has BRAF V600E and TP53 mutations, SW-1736 has a BRAF V600E mutation, and C-643 has an HRAS mutation. The cell lines were authenticated by short tandem repeat profiling. The passage number of the cells used in the experiments ranged from 10 to 20 passages.

\section{National Institutes of Health Chemical Genomics Center Pharmaceutical Collection library screening}

The National Institutes of Health Chemical Genomics Center Pharmaceutical Collection (NPC) consists of 3282 small-molecule compounds, of which $46 \%$ are drugs approved for human or animal use by the U.S. Food and Drug Administration (Huang et al. 2011). Detailed information on the drugs in this collection can be found at http://spotlite.nih.gov/npc. Test compounds from the NPC library were prepared as described previously (Zhang et al. 2012).

\section{Quantitative high-throughput proliferation assay}

Cell viability after compound treatment was measured using a luciferase-coupled ATP quantitation assay (CellTiter-Glo; Promega) on the 8505C, C-643, and SW-1736 cells as described previously (Nilubol et al. 2012, Zhang et al. 2012).

\section{Cell proliferation}

Cell proliferation assays were performed in quadruplicate. 8505C, SW-1736, and C-643 cells were plated in black 96-well plates at a concentration of $2-4 \times 10^{3}$ cells/well, depending on the cell line, in $100 \mu \mathrm{l}$ of culture medium. After $24 \mathrm{~h}$ (day 0), $100 \mu \mathrm{l}$ of fresh culture medium containing carfilzomib or vehicle were added to each well. CyQUANT (Invitrogen) proliferation assays were performed at $0,2,4$, and 6 days, according to the manufacturer's instructions. The cell number was determined using a 96-well fluorescence microplate reader (Molecular Devices, Sunnyvale, CA, USA) at an absorbance of $485 \mathrm{~nm} / 538 \mathrm{~nm}$.

\section{Cell cycle assay}

Cells were plated in six-well plates at a density of $6 \times 10^{4}$ to $12 \times 10^{4}$ cells/well, depending on the cell line, in $2 \mathrm{ml}$ of culture medium. After $24 \mathrm{~h}$, fresh culture medium containing carfilzomib or vehicle was added to each well. Following treatment for $18 \mathrm{~h}$, the cells were harvested, fixed with cold $70 \%$ ethanol for $30 \mathrm{~min}$ at $4{ }^{\circ} \mathrm{C}$, and incubated in the dark with RNase $(100 \mathrm{mg} / \mathrm{ml})$ and propidium iodide $(50 \mathrm{mg} / \mathrm{ml})$ for $30 \mathrm{~min}$ at $37^{\circ} \mathrm{C}$. A total of 20000 nuclei were examined by flow cytometry using a FACSCalibur flow cytometer (Becton Dickinson, Franklin Lakes, NJ, USA) and the resulting data were analyzed using the ModFit Software (Verity Software House, Topsham, ME, USA).

\section{Apoptosis assay}

To determine whether drug treatment resulted in apoptosis, we used the APO-BrdU flow cytometry analysis assay (BD Pharmingen, San Jose, CA, USA). We also used the Caspase-Glo 3/7 assay (Promega) to measure caspase

Published by Bioscientifica Ltd 
activity. 8505C, SW-1736, and C-643 cells were plated in white 96-well plates at a density of $2.2-4 \times 10^{3}$ cells/well, depending on the cell line. After $24 \mathrm{~h}$, fresh culture medium containing carfilzomib or vehicle was added. After $24-48 \mathrm{~h}$, cells were analyzed by APO-BrdU flow cytometry analysis and for caspase $3 / 7$ activity using the Caspase-Glo 3/7 assay kit according to the manufacturer's instructions. The relative luminescence (which is proportional to caspase $3 / 7$ activity) was calculated and normalized to the total cell number.

\section{Western blot analysis}

Total protein lysates were separated by SDS-PAGE, transferred onto a nitrocellulose membrane, and immunostained with the following antibodies overnight at $4{ }^{\circ} \mathrm{C}$ : anti-p2 $7^{\text {Kip1 }}$ (1:250 dilution, BD Transduction Laboratories, San Jose, CA, USA); anti-ATF4 (1:250 dilution, Santa Cruz Biotechnology); anti-N-cadherin (1:1000 dilution, EMD Millipore, Billerica, MA, USA); and anti$\beta$-actin (1:3000 dilution, Santa Cruz Biotechnology). Anti-human $\beta$-actin was used as a loading control. The membranes were incubated with the appropriate HRP-conjugated IgG (anti-rabbit antibody at 1:3000 dilution, Cell Signaling Technology, Danvers, MA, USA, or anti-mouse antibody at 1:10000 dilution, Santa Cruz Biotechnology). An ECL assay (Thermo Scientific, Rockford, IL, USA) was used to detect proteins.

\section{In vivo mouse studies}

A metastatic ATC mouse model was utilized for all in vivo studies of carfilzomib treatment (Zhang et al. 2014). Stably transfected $8505 \mathrm{C}$ cells, containing a linearized pGL4.51[luc2/CMV/Neo] vector luciferase reporter $\left(8505 \mathrm{C} /\right.$ Luc cells), were used. NOD.Cg-Prkdc $c^{\text {sid }}$ $I l 2 \mathrm{rg}^{t m 1 W_{j l}} /$ SzJ mice received injections of 8505C-Luc2 cells (30 000 cells/mouse) via the tail vein. Metastases were confirmed at 1 week after tumor cell implantation, using bioluminescence imaging and the Xenogen in vivo imaging system. The images were analyzed using the IVIS Living Image Software (Caliper Life Sciences, Inc., Hopkinton, MA, USA). The mice were maintained according to the guidelines of the National Cancer Institute's Animal Research Advisory Committee.

Carfilzomib (Onyx Pharmaceuticals, San Francisco, CA, USA) was reconstituted with 10\% Captisol (Ligand Technology, La Jolla, CA, USA), according to the manufacturer's instructions. On day 7 after tumor cell injection, mice were stratified into carfilzomib and vehicle treatment groups. Carfilzomib (6 mg/kg) or vehicle was administered intraperitoneally, three times a week. Treatment was continued until death or upon reaching humane criteria endpoints.

To assess the effects of carfilzomib on tumor metastasis, pretreatment in vivo mouse studies were also completed. NOD.Cg-Prkdc $c^{\text {scid }} I l 2 \mathrm{rg}^{\text {tm } 1 \mathrm{Wil}} / \mathrm{SzJ}$ mice first received intraperitoneal injections of either carfilzomib $(6 \mathrm{mg} / \mathrm{kg}$ ) or vehicle (10\% Captisol) for 2 consecutive days. The following day, the mice received injections of $8505 \mathrm{C}$ Luc2 cells (30 000 cells/mouse) via the tail vein. On day 7 after tumor cell injection, carfilzomib $(6 \mathrm{mg} / \mathrm{kg}$ ) or vehicle was administered intraperitoneally, three times a week.

\section{Statistical analyses}

To determine compound activity in the qHTS assay, the titration-response data for each sample were plotted and modeled by a four-parameter logistic fit, yielding $\mathrm{IC}_{50}$ (concentration of half-maximal inhibition) and efficacy (maximal response) values. Raw plate reads for each titration point were first normalized relative to positive control-only (tetraoctylammonium bromide, 100\% inhibition) and negative control-only (DMSO, 0\% inhibition) wells. Curve fits were then classified by criteria described previously (Inglese et al. 2006). Based on the quality of curve fit and efficacy, screened compounds were then classified into three categories: active, inactive, and inconclusive (Zhang et al. 2012).

To assess drug activity on the basis of the mechanism of action of the drug, we performed enrichment analysis by therapeutic category. The enrichment score is the ratio of the number of active drugs to the total number of tested drugs in the same therapeutic category based on the mechanism of action of the drug. To further assess active compounds, we also completed pharmacokinetic analyses. The candidate compound was selected for validation based on a demonstrated antiproliferative efficacy of over $80 \%$, an $\mathrm{IC}_{50}$ less than $1 \mu \mathrm{M}$, high maximum achievable plasma concentration $\left(C_{\text {max }}\right)$, and a wide therapeutic window (defined as having an $\mathrm{IC}_{50}$ less than the $C_{\max }$ ).

Statistical analyses were performed using the GraphPad Prism 5 Software (GraphPad Software, La Jolla, CA, USA). Data were analyzed using a two-tailed $t$-test and the Mann-Whitney $U$ test. Differences in survival for in vivo studies were assessed using Kaplan-Meier survival curves. A $P$ value $<0.05$ was considered statistically significant. Data are expressed as mean \pm s.D. or mean \pm s.E.M.

Published by Bioscientifica Ltd 
Table 1 Pharmacokinetic analysis of proteasome inhibitors screened using qHTS

\begin{tabular}{|c|c|c|c|c|c|c|c|c|c|c|c|}
\hline \multirow[b]{2}{*}{ Compound } & \multirow[b]{2}{*}{$\begin{array}{c}\mathrm{C}_{\max } \\
(\mathrm{ng} / \mathrm{ml})\end{array}$} & \multicolumn{3}{|c|}{$8505 C$ cell line } & \multicolumn{3}{|c|}{ C-643 cell line } & \multicolumn{4}{|c|}{ SW-1736 cell line } \\
\hline & & $\begin{array}{l}\text { Curve } \\
\text { class }\end{array}$ & $\begin{array}{l}I_{50} \\
(\mu \mathrm{M})\end{array}$ & $\begin{array}{c}\text { Maximum } \\
\text { attainable } \\
\text { response (\%) }\end{array}$ & $\begin{array}{l}\text { Curve } \\
\text { class }\end{array}$ & $\begin{array}{l}\mathrm{IC}_{50} \\
(\mu \mathrm{M})\end{array}$ & $\begin{array}{c}\text { Maximum } \\
\text { attainable } \\
\text { response }(\%)\end{array}$ & $\begin{array}{l}\text { Curve } \\
\text { class }\end{array}$ & $\begin{array}{l}I_{50} \\
(\mu \mathrm{M})\end{array}$ & $\begin{array}{c}\text { Maximum } \\
\text { attainable } \\
\text { response (\%) }\end{array}$ & $\begin{array}{l}\text { Activity } \\
\text { category }\end{array}$ \\
\hline Carfilzomib & 4232 & -1.1 & 0.004 & -121 & -1.1 & 0.012 & -92 & -1.1 & 0.03 & -89 & Active \\
\hline Bortezomib & 112 & -1.1 & 0.013 & -107 & -1.1 & 0.004 & -106 & -1.1 & 0.017 & -84 & Active \\
\hline Ixazomib & NA & -1.1 & 0.042 & -108 & -1.1 & 0.013 & -93 & -1.1 & 0.13 & -108 & Active \\
\hline
\end{tabular}

NA, not available. $C_{\max }$ maximum achievable serum concentration.

\section{Results}

\section{qHTS of drug library}

To identify compounds with potential anticancer activity against ATC, we screened the NPC library using qHTS. This strategy used concentration-response curve information to identify 100 compounds that were active in all three tested ATC cell lines (8505C, C-643, and SW-1736). Enrichment analysis of active agents in each drug category revealed that proteasome inhibitors were among the most active drug classes screened. Among the proteasome inhibitors, carfilzomib, a second-generation proteasome inhibitor, was one of the most active agents, with a low
$\mathrm{IC}_{50}$ and highest efficacy in ATC cells and a high achievable serum concentration in humans (Table 1). Carfilzomib not only had an efficacy $\geq 89 \%$ in all three screened cell lines, but also had a high $C_{\max }(5.9 \mu \mathrm{M})$ and high potency, as reflected by an $\mathrm{IC}_{50}$ in the nanomolar range. Most importantly, the $\mathrm{IC}_{50}$ was found to be well below the $C_{\text {max }}$, indicating that carfilzomib has a wide therapeutic window. We then compared the activity of carfilzomib with drugs used in patients with ATC, such as doxorubicin and docetaxel (Smallridge et al. 2012). The activity of carfilzomib was better than those of doxorubicin and docetaxel, with a lower $\mathrm{IC}_{50}$ and higher efficacy in all three ATC cell lines (Fig. 1A).
A

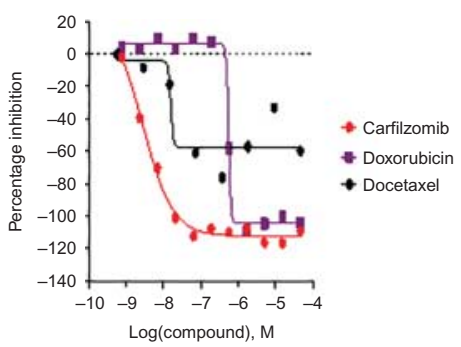

B

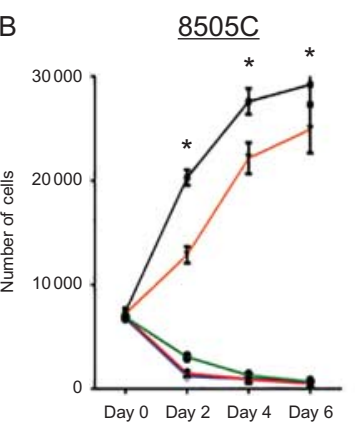

$\underline{\mathrm{C}-643}$
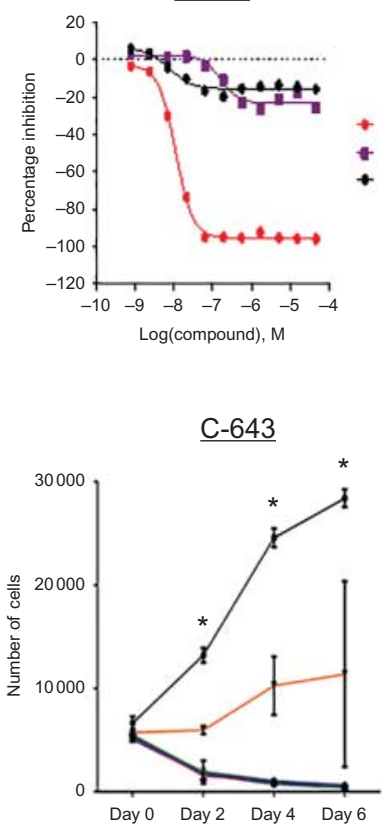

SW-1736
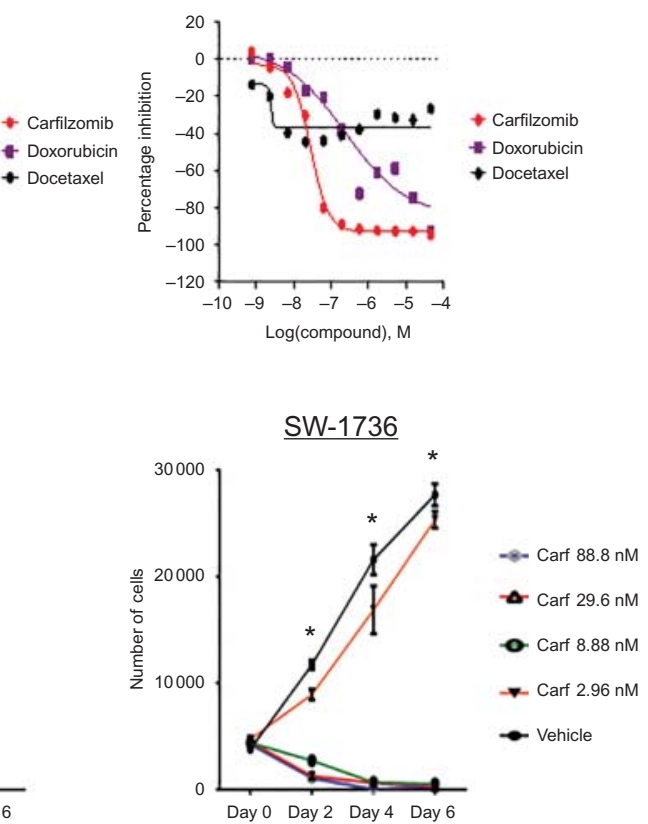

\section{Figure 1}

(A) Comparison of dose-response curves for carfilzomib, doxorubicin, and docetaxel in three ATC cell lines. Carfilzomib has a greater potency and a lower IC $_{50}$ in all three ATC cell lines. (B) Carfilzomib inhibits cellular proliferation and causes cell death. The effect of carfilzomib was
(C) 2015 Society for Endocrinology Printed in Great Britain determined using three ATC cell lines: 8505C, C-643, and SW-1736, and the CyQUANT assay. Cells were treated at concentrations (2.96-88.8 nM) within the clinically achievable range. ${ }^{\star} P<0.05$ for all concentrations compared with vehicle control.

Published by Bioscientifica Ltd. 
A
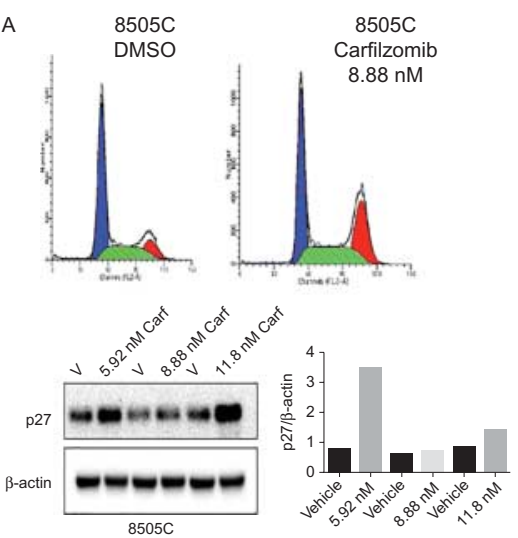
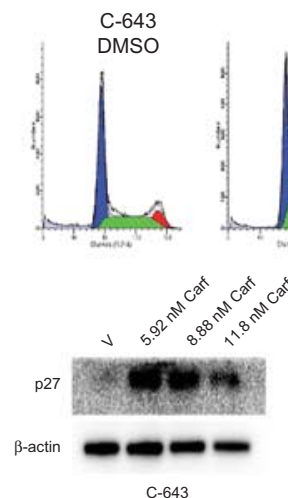

C-643 Carfilzomib
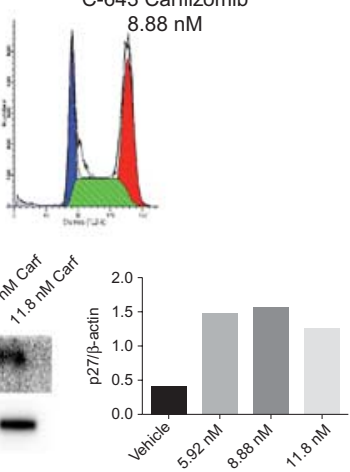

C
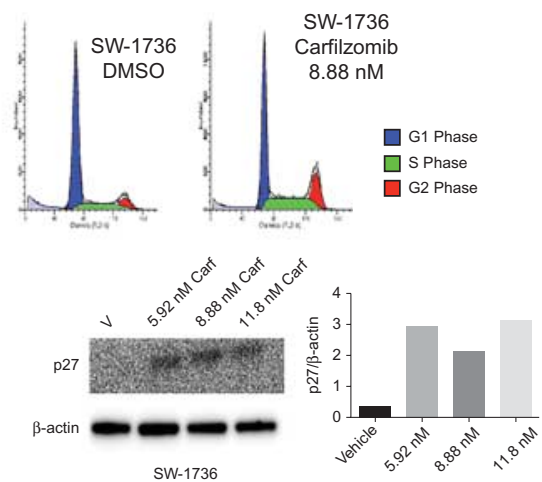

Figure 2

Carfilzomib induces G2/M cell cycle arrest and upregulates p27 expression. Upper panels: subconfluent $8505 C$ (A), C-643 (B), and SW-1736 (C) ATC cells were treated with carfilzomib or vehicle for $18 \mathrm{~h}$. Cells were then harvested for flow cytometry analysis as described in the Materials and methods. Lower left panels: for corresponding western blot analyses, subconfluent

\section{Carfilzomib inhibits cell proliferation and induces cell death}

To confirm carfilzomib's growth-inhibitory effect in ATC cells, we validated our qHTS results. Treatment with carfilzomib inhibited cellular proliferation and induced cell death (Fig. 1B). This antiproliferative effect was observed at concentrations up to 1000-fold lower than the drug's $C_{\max }$, the concentration at which most of the drug's side effects are likely to occur. Furthermore, at concentrations as low as $8.88 \mathrm{nM}$, carfilzomib not only inhibited cancer cell growth, but also induced over $90 \%$ cell death within $48 \mathrm{~h}$ of treatment.

\section{Carfilzomib induces cell cycle arrest and upregulates p27}

Given the antiproliferative and cytotoxic effects of carfilzomib in proliferation assays, we performed cell cycle analyses to explore the underlying mechanisms of carfilzomib's activity in ATC cells. According to our flow cytometry analysis, carfilzomib treatment resulted in ATC cells accumulating in the G2/M phase within $18 \mathrm{~h}$ of treatment (Fig. 2). The relative sensitivity of the ATC cell lines to carfilzomib was associated with the accumulation of cells in G2/M. In order to further clarify the mechanism behind carfilzomib-induced cell cycle arrest, we examined the drug's effect on several important cell cycle regulatory proteins: p21 (CDKN1A), p27 (CDKN1B), and p53 (TP53). Following treatment with carfilzomib, we observed an increase in p27 protein expression in all three ATC cell lines (Fig. 2),
$8505 C$ (A), C-643 (B), and SW-1736 (C) ATC cells were treated with carfilzomib or vehicle for $18 \mathrm{~h}$. Cells were then lysed and analyzed by western blot assay. $\beta$-actin expression was used as a loading control. Lower right panels: band densitometry measurements of protein bands.

but no effect on p53 and p21 protein expression (not shown).

\section{Carfilzomib induces caspase-dependent apoptosis}

As carfilzomib also induced cell death, we then determined whether this effect was mediated through apoptosis, as has been observed with other proteasome inhibitors. Carfilzomib treatment of ATC cells resulted in apoptosis according to APO-BrdU flow cytometry analysis (Fig. 3). We also measured caspase activity in the ATC cell lines after $24 \mathrm{~h}$, with and without carfilzomib treatment, and found a three- to eightfold increase in caspase activity in the treated cells (Fig. 3).

To further characterize the effect of carfilzomib on dysregulated apoptosis-regulatory proteins in ATC, we evaluated the expression of ATF4, an anti-apoptotic transcription factor known to regulate the prosurvival autophagy pathway, as well as to mediate chemoresistance to proteasome inhibitors such as bortezomib (Milani et al. 2009, Rzymski et al. 2009). Following treatment with carfilzomib, we observed a decrease in the expression of ATF4 in all three ATC cell lines (Fig. 3).

\section{Carfilzomib inhibits tumor growth and prolongs survival in vivo}

We further validated the antitumor activity of carfilzomib in an in vivo metastasis mouse model, a more clinically relevant model for ATC. Following 3 weeks of treatment, there was less metastatic tumor burden and, more

Published by Bioscientifica Ltd 
A $\quad 8505 C$

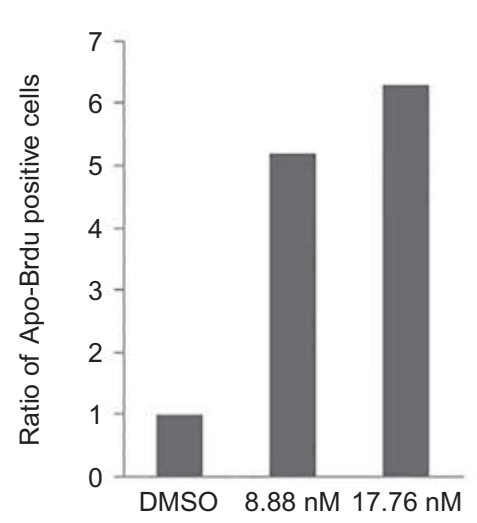

B

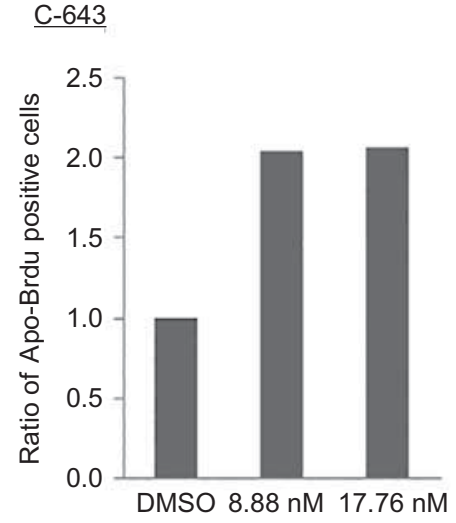

C

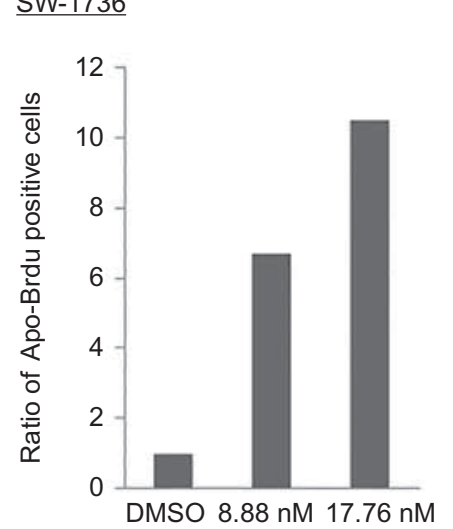

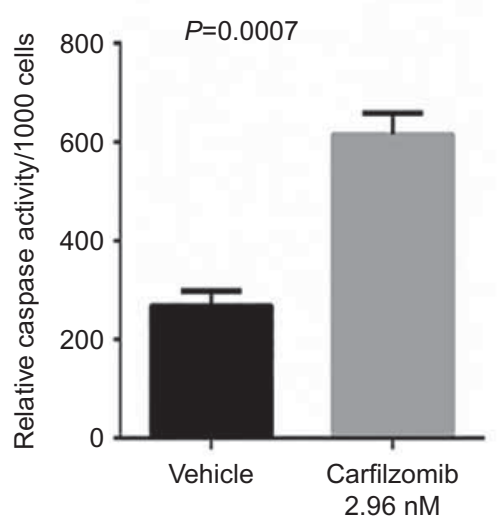
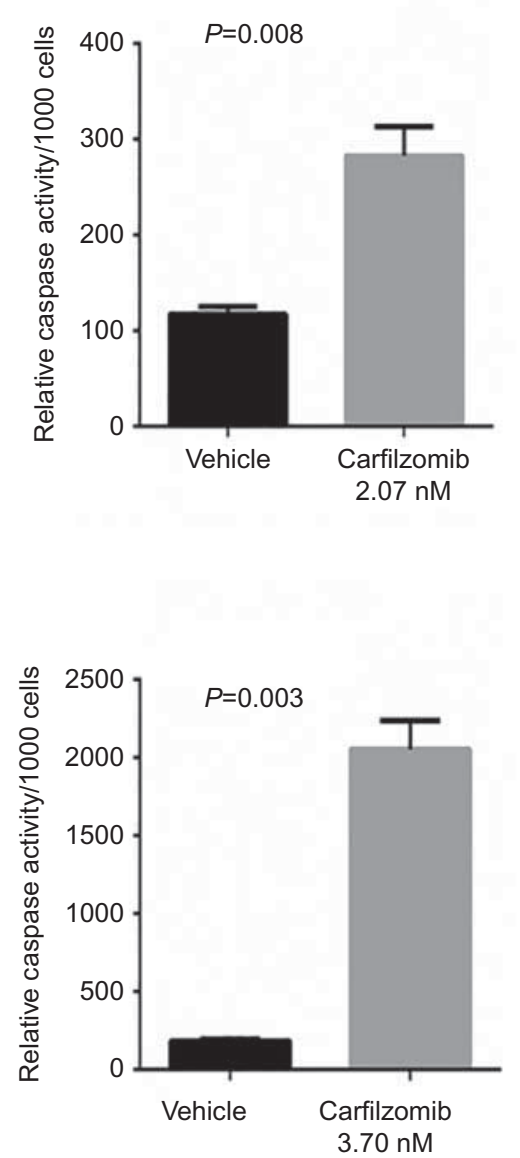
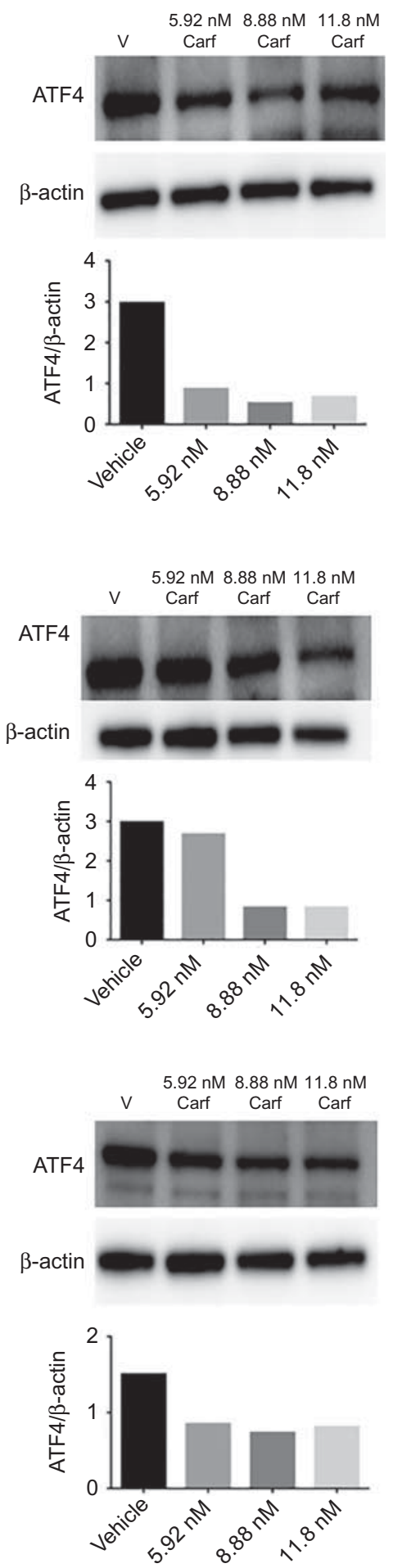

Figure 3

Carfilzomib induces apoptosis and increases caspase 3/7 activity and downregulates expression of anti-apoptotic ATF4. Left panels show fold increase in apoptotic cells with carfilzomib treatment. Middle panels show apoptosis with increased caspase 3/7 activity in carfilzomib-treated cells. Right panels show western blots for ATF4 detection. The charts below show the band densitometry measurement. Apoptosis data shown represent treatment for $24 \mathrm{~h}$ with carfilzomib or vehicle. For corresponding western blots, subconfluent $8505 C$ (A), C-643 (B), and SW-1736 (C) ATC cells were treated with carfilzomib or vehicle for $24 \mathrm{~h}$ 


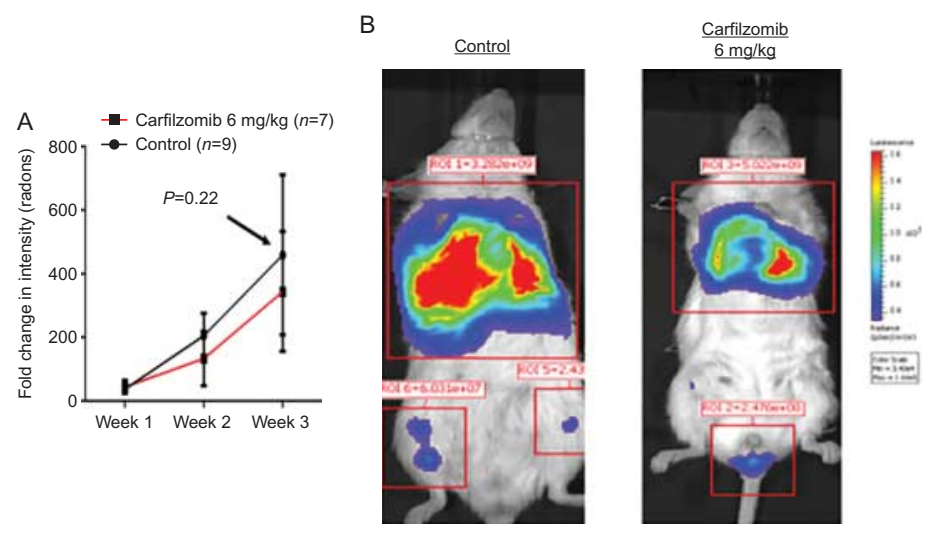

C
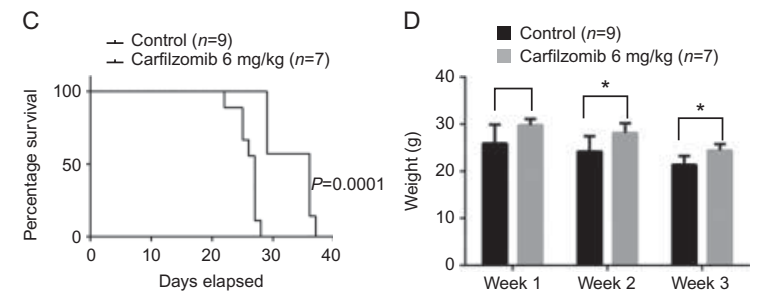

\section{Figure 4}

Carfilzomib demonstrates antitumor activity in vivo. (A) Carfilzomib shows a trend of metastatic tumor growth inhibition and reduces the number of metastases sites. Changes in tumor burden measured weekly by measuring luciferase activity of $8505 \mathrm{C}$-Luc2 cells injected via the tail vein. The $y$-axis of the graph corresponds to the fold change in intensity, relative to the initial tumor burden. (B) Representative images of mice showing the extent of

importantly, a statistically significant increase in overall survival in mice with heavy tumor burden (Fig. 4A, B and C). Interestingly, mice treated with carfilzomib also had a significantly lower rate of distant metastasis (fewer sites of bone and liver metastasis) beyond the lung tumor site compared with the vehicle group (Fig. 4B). These results indicate that carfilzomib not only exhibits antitumor activity in vivo, but may also directly inhibit metastasis of tumor cells. A statistically significant decrease in weight of untreated mice was observed compared with the treated mice beginning in week 2 , probably due to a greater tumor burden (Fig. 4D). Mice treated with carfilzomib developed transient gastrointestinal distress, with diarrhea and loss of appetite, following the first week of treatment (beginning on day 9). Symptoms were effectively managed with fluid repletion and resolved by day 13 .

\section{Carfilzomib inhibits distant metastasis in vivo and reduces $\mathrm{N}$-cadherin expression}

ATC metastasis and local invasion, and recurrence after complete resection, are common, thus an effective therapy for ATC could be an agent that inhibits cancer progression (Ain 1998, Besic \& Gazic 2013). Given the lower rate of progressive metastases we observed in our in vivo study in mice that already carry a heavy tumor burden, we further investigated whether carfilzomib could inhibit metastases in vivo, using a pretreatment model. We found that pretreatment with carfilzomib dramatically inhibited ATC progression (Fig. 5A and B). Furthermore, mice tumor burden and intensity of luciferase activity at week 3 . Red squares in the images indicate sites of metastases. (C) Carfilzomib prolongs overall survival of mice with metastatic ATC $(P=0.0001)$. (D) A significant difference in weight was observed between treated and untreated groups of mice after 2 and 3 weeks of treatment. ${ }^{*} P<0.05$.

pretreated with carfilzomib also had profound inhibition of established lung tumor growth (Fig. 5), as well as prolonged survival compared with the controls (Fig. 5C). A statistically significant decrease in weight of untreated mice was observed, relative to the pretreated mice (Fig. 5D). Pretreated mice also developed transient gastrointestinal distress following the first week of treatment, which again resolved with fluid repletion.

Loss of epithelial markers and acquisition of mesenchymal markers, mediated by the epithelial-mesenchymal transition (EMT) process, are known to increase the metastatic ability of cancer cells (Chaffer \& Weinberg 2011). Given the significantly lower rate of metastasis we observed in the in vivo pretreatment experiments, we examined whether carfilzomib activity in ATC also inhibits the expression of EMT mediators such as $\mathrm{N}$-cadherin and vimentin. Carfilzomib treatment decreased the expression of N-cadherin in ATC cells (Fig. 5E), but no changes were observed in the vimentin expression level (not shown).

\section{Discussion}

This study has five major findings. First, we have shown the utility of qHTS of clinical drug libraries as an efficient approach for rapidly screening drug activity in multiple ATC cell lines. Secondly, we have demonstrated that carfilzomib, a second-generation proteasome inhibitor, has growth-inhibitory and cytotoxic effects in ATC cells. Thirdly, carfilzomib's antiproliferative activity in

Published by Bioscientifica Ltd 

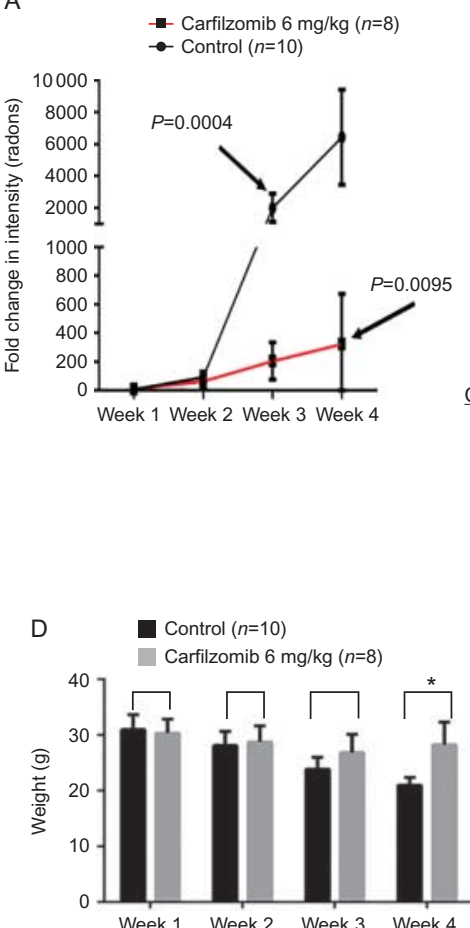

B

Control

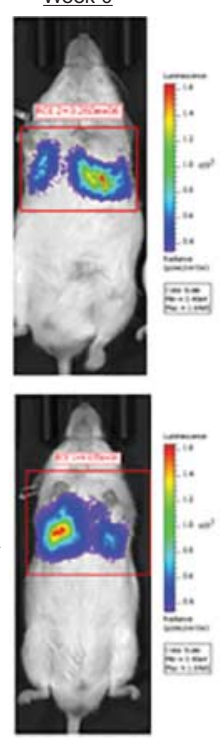

Week 4

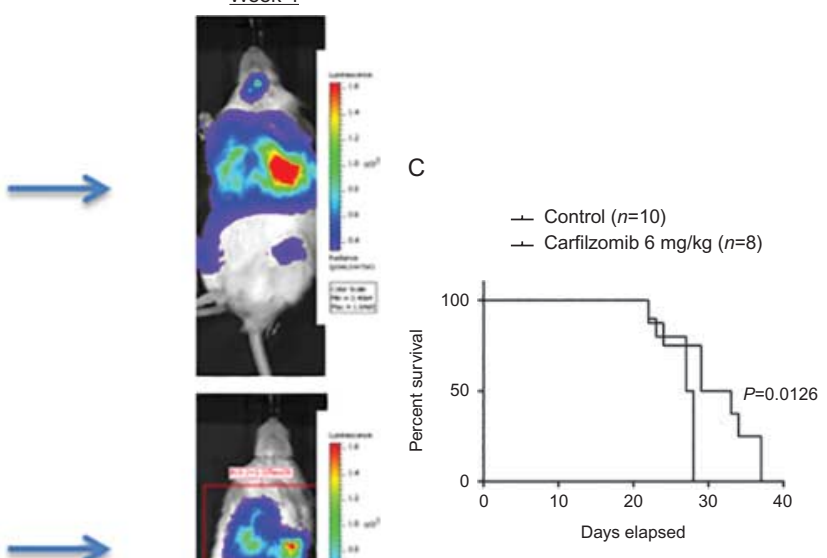

Figure 5

Carfilzomib inhibits metastasis of ATC. (A) Pretreatment with carfilzomib significantly inhibits distant metastasis and established tumor growth. Changes in tumor burden assessed weekly by measuring the luciferase activity of 8505C-Luc2 cells injected via the tail vein. The $y$-axis of the graph corresponds to fold change in intensity, relative to initial tumor burden. (B) Representative images of mice showing the extent of tumor burden and intensity of luciferase activity. (C) Pretreatment with carfilzomib prolongs overall survival of mice with metastatic ATC ( $P=0.0126)$. (D) A statistically significant difference in weight was observed between mice pretreated with carfilzomib and those pretreated with vehicle at week $4 .{ }^{*} P<0.05$. (E) Carfilzomib decreases $\mathrm{N}$-cadherin expression. Subconfluent $8505 \mathrm{C}$, C-643, and SW-1736 ATC cells were treated with carfilzomib or vehicle as shown for $24 \mathrm{~h}$. Cells were then lysed and analyzed using a western blot assay.
ATC is associated with induction of $\mathrm{G} 2 / \mathrm{M}$ phase arrest and increased p27 expression, and caspase-dependent apoptosis. Fourthly, carfilzomib showed potent antitumor activities in vivo, including tumor growth inhibition and prolonged survival in ATC metastasis mouse models. Finally, carfilzomib treatment also inhibited cancer progression in vivo, with reduced expression of $\mathrm{N}$-cadherin.

To identify carfilzomib from the NPC chemical compound libraries, we conducted a qHTS using three ATC cell lines (8505C, C-643, and SW-1736). Proteasome inhibitors were among the most active drug categories. The ubiquitin proteasome pathway (UPP) is responsible for the degradation of eukaryotic cellular proteins and is an important regulator of cancer initiation and progression (Voorhees et al. 2003, Adams 2004).
Bortezomib, the first inhibitor of the UPP to be used in clinical studies, has been extensively studied for both hematological and solid cancers, including thyroid cancer (Hideshima et al. 2001, Papandreou et al. 2004, Mitsiades et al. 2006, Altmann et al. 2012, Wunderlich et al. 2012). Results of recent preclinical studies have also indicated that bortezomib inhibits ATC cell proliferation and induces caspase-dependent apoptosis in vitro, with potent antitumor effects in vivo as well (Mitsiades et al. 2006, Conticello et al. 2007, Altmann et al. 2012, Wunderlich et al. 2012). The clinical efficacy of bortezomib, however, is challenged by the rapid development of drug resistance, as it is not an irreversible proteasome inhibitor like carfilzomib, and also by the dose-limiting neurotoxicity associated with bortezomib treatment (Ruckrich et al. 2009, Jain et al. 2011). Given these limitations, carfilzomib represents

Published by Bioscientifica Ltd. 
a potentially more attractive systemic agent against ATC. It is an irreversible inhibitor of the $20 \mathrm{~S}$ proteasome, hence carfilzomib causes a more sustained inhibition of cellular proteasome activity, requiring new protein synthesis for functional recovery (Groll et al. 2006, Demo et al. 2007). Consequently, carfilzomib has also been found to be far more cytotoxic, compared with bortezomib, in a variety of human tumor cell lines, with less toxicity to normal or nontransformed cells (Demo et al. 2007, Parlati et al. 2009). Furthermore, carfilzomib shows minimal activity against targets other than the chymotrypsin-like activity of the $20 \mathrm{~S}$ proteasome, and is therefore better tolerated than comparable first-generation proteasome inhibitors that have significant cytotoxicity in normal cells at high concentrations (Demo et al. 2007, O'Connor et al. 2009). Our own pharmacokinetic analysis of carfilzomib further highlighted its advantages over bortezomib, including greater potency and/or efficacy and a wider therapeutic window. Furthermore, screening data comparing the antiproliferative effects of carfilzomib with ATC chemotherapeutic agents, such as doxorubicin and docetaxel, indicated that carfilzomib had greater efficacy and potency.

We found that carfilzomib has potent anticancer activities against ATC, inducing dose- and time-dependent growth inhibition that is associated with increased G2/M arrest. The cyclin-dependent-kinase inhibitor p27 is an important cell cycle regulator that plays an essential role in the induction and maintenance of $\mathrm{G} 2 / \mathrm{M}$ phase arrest in response to anticancer drugs (Cuadrado et al. 2009). Results of recent studies have indicated that there is reduced expression of p27 in a variety of human cancer cell lines (Catzavelos et al. 1997, Yasui et al. 1997). Moreover, this decreased expression is believed to be mediated by increased proteasome degradation and not altered gene expression (Loda et al. 1997). Given these findings, it is not surprising that we found upregulation of p27 with carfilzomib treatment. This indicates that increased p27 expression probably promotes the observed arrest of ATC cells in G2/M phase but may not be the only cell-cycle regulatory protein that mediates this effect.

Induction of p27 expression and cell cycle arrest has also been demonstrated to play an important role in caspase-dependent apoptosis, though details of this mechanism remain unclear (Wang et al. 1997, Kudo et al. 2000). As expected, we observed an increase in caspase 3/7 activity in ATC cells following treatment with carfilzomib. Analysis of apoptosis-related protein expression revealed decreased expression of an anti-apoptotic protein, ATF4, with carfilzomib treatment. ATF4 belongs to a large family of basic region/leucine zipper transcription factors, and mediates the cellular hypoxic response to the unfolded protein response (Ameri \& Harris 2008). The protective role of ATF4 during cellular stress has been well documented, activating genes that promote restoration of normal ER function and prosurvival pathways, such as autophagy (Ameri \& Harris 2008, Rzymski et al. 2009, Jiang et al. 2013). Given that we observed a decrease in ATF4 expression with carfilzomib treatment, this indicates that carfilzomib promotes cell death by overcoming ATF4-mediated autophagy. Recent evidence has indicated that induction of ATF4 also plays a critical role in resistance to many chemotherapeutic agents, including bortezomib. By activating pathways like autophagy, ATF4 helps to relieve the protein overload in bortezomib-treated cells (Milani et al. 2009, Rzymski et al. 2009). By downregulating ATF4 expression, carfilzomib appears to also overcome this ATF4-mediated chemoresistance.

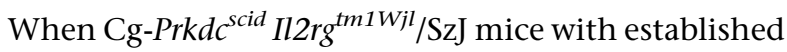
ATC metastases were treated with carfilzomib $(6 \mathrm{mg} / \mathrm{kg})$, we saw a trend of tumor growth inhibition during a 3-week treatment period. Furthermore, treatment resulted in a statistically significant increase in overall survival. The natural history of ATC is defined by its propensity to invade and metastasize widely (Ain 1998, Besic \& Gazic 2013). Consequently, we also examined the effect of carfilzomib on ATC progression using an in vivo pretreatment model. While the initial lung tumor burden on day 7 following inoculation was not significantly different between pretreated and vehicle groups, we did observe significantly fewer metastases over the subsequent 4-week treatment period. Finally, pretreated mice also displayed a significant increase in overall survival, probably a result of the decreased metastatic tumor burden associated with carfilzomib treatment.

Metastasis is associated with the loss of epithelial features and acquisition of mesenchymal properties, including increased invasiveness and resistance to apoptosis, through EMT (Chaffer \& Weinberg 2011). Proteasome inhibition has been associated with both the induction and inhibition of EMT, depending on the specific human cancer cell line (Baritaki et al. 2009, Kim et al. 2011). However, to our knowledge, no study to date has examined the effect of proteasome inhibition on EMT in thyroid cancer. Given our in vivo pretreatment findings, we anticipated that proteasome inhibition would repress EMT. After treating ATC cells for $24 \mathrm{~h}$ with carfilzomib, we observed a dose-dependent decrease in expression of the EMT protein N-cadherin. These results may explain the decreased rate of distant

Published by Bioscientifica Ltd. 
metastasis observed in vivo following carfilzomib pretreatment. On the basis of these findings, carfilzomib may also prove to be an effective therapy for ATC in the adjuvant setting.

In conclusion, we used qHTS to test 3282 different compounds against ATC and identified a second-generation proteasome inhibitor, carfilzomib, as one among the most active compounds. We have demonstrated that carfilzomib has strong antitumor effects in human ATC cells in vitro, inducing cycle arrest and caspase-dependent apoptosis. The antitumor activity of carfilzomib was further validated in vivo, using an ATC metastasis mouse model that recapitulates the clinical features of ATC. Thus, carfilzomib is a promising therapeutic agent for ATC.

\section{Declaration of interest}

The authors declare that there is no conflict of interest that could be perceived as prejudicing the impartiality of the research reported.

\section{Funding}

This research was supported by the intramural research programs of the Center for Cancer Research, National Cancer Institute, National Institutes of Health, as well as the National Institutes of Health (NIH) Medical Research Scholars Program, a public-private partnership supported jointly by the $\mathrm{NIH}$, and generous contributions to the Foundation for the NIH from Pfizer, Inc., the Doris Duke Charitable Foundation, Alexandria Real Estate Equities, Inc., Mr and Mrs Joel S Marcus, and the Howard Hughes Medical Institute, as well as other private donors. For a complete list, please visit the Foundation website at: http://fnih.org/work/education-training-0/medicalresearch-scholars-program.

\section{Author contribution statement}

A Mehta, L Zhang, and E Kebebew conceived and designed study. A Mehta, L Zhang, M Boufraqech, Y Zhang, D Patel, and M Shen participated in the acquisition of data. A Mehta, L Zhang, M Boufraqech, Y Zhang, D Patel, $M$ Shen, and $E$ Kebebew participated in analysis and interpretation of data. A Mehta, L Zhang, M Boufraqech, Y Zhang, D Patel, M Shen, and E Kebebew participated in drafting the article. L Zhang and E Kebebew participated in critical revision of the article.

\section{References}

Adams J 2004 The development of proteasome inhibitors as anticancer drugs. Cancer Cell 5 417-421. (doi:10.1016/S1535-6108(04)00120-5)

Ain KB 1998 Anaplastic thyroid carcinoma: behavior, biology, and therapeutic approaches. Thyroid 8 715-726. (doi:10.1089/thy.1998. 8.715)

Altmann A, Markert A, Askoxylakis V, Schoning T, Jesenofsky R, Eisenhut M \& Haberkorn U 2012 Antitumor effects of proteasome inhibition in anaplastic thyroid carcinoma. Journal of Nuclear Medicine 53 1764-1771. (doi:10.2967/jnumed.111.101295)

Ameri K \& Harris AL 2008 Activating transcription factor 4. International Journal of Biochemistry \& Cell Biology 40 14-21. (doi:10.1016/j.biocel. 2007.01.020)
Baritaki S, Chapman A, Yeung K, Spandidos DA, Palladino M \& Bonavida B 2009 Inhibition of epithelial to mesenchymal transition in metastatic prostate cancer cells by the novel proteasome inhibitor, NPI-0052: pivotal roles of Snail repression and RKIP induction. Oncogene $\mathbf{2 8}$ 3573-3585. (doi:10.1038/onc.2009.214)

Besic N \& Gazic B 2013 Sites of metastases of anaplastic thyroid carcinoma: autopsy findings in 45 cases from a single institution. Thyroid $\mathbf{2 3}$ 709-713. (doi:10.1089/thy.2012.0252)

Catzavelos C, Bhattacharya N, Ung YC, Wilson JA, Roncari L, Sandhu C, Shaw P, Yeger H, Morava-Protzner I, Kapusta L et al. 1997 Decreased levels of the cell-cycle inhibitor $\mathrm{p} 27^{\mathrm{Kip} 1}$ protein: prognostic implications in primary breast cancer. Nature Medicine 3 227-230. (doi:10.1038/nm0297-227)

Chaffer CL \& Weinberg RA 2011 A perspective on cancer cell metastasis. Science 331 1559-1564. (doi:10.1126/science.1203543)

Conticello C, Adamo L, Giuffrida R, Vicari L, Zeuner A, Eramo A, Anastasi G, Memeo L, Giuffrida D, Iannolo G et al. 2007 Proteasome inhibitors synergize with tumor necrosis factor-related apoptosis-induced ligand to induce anaplastic thyroid carcinoma cell death. Journal of Clinical Endocrinology and Metabolism 92 1938-1942. (doi:10.1210/ jc.2006-2157)

Cuadrado M, Gutierrez-Martinez P, Swat A, Nebreda AR \& FernandezCapetillo O 2009 p $27^{\mathrm{Kip} 1}$ stabilization is essential for the maintenance of cell cycle arrest in response to DNA damage. Cancer Research 69 8726-8732. (doi:10.1158/0008-5472.CAN-09-0729)

Demo SD, Kirk CJ, Aujay MA, Buchholz TJ, Dajee M, Ho MN, Jiang J, Laidig GJ, Lewis ER, Parlati F et al. 2007 Antitumor activity of PR-171, a novel irreversible inhibitor of the proteasome. Cancer Research 67 6383-6391. (doi:10.1158/0008-5472.CAN-06-4086)

Granata R, Locati L \& Licitra L 2013 Therapeutic strategies in the management of patients with metastatic anaplastic thyroid cancer: review of the current literature. Current Opinion in Oncology 25 224-228. (doi:10.1097/CCO.0b013e32835ff44b)

Groll M, Huber R \& Potts BC 2006 Crystal structures of Salinosporamide A (NPI-0052) and B (NPI-0047) in complex with the 20S proteasome reveal important consequences of $\beta$-lactone ring opening and a mechanism for irreversible binding. Journal of the American Chemical Society 128 5136-5141. (doi:10.1021/ja058320b)

Hideshima T, Richardson P, Chauhan D, Palombella VJ, Elliott PJ, Adams J \& Anderson KC 2001 The proteasome inhibitor PS-341 inhibits growth, induces apoptosis, and overcomes drug resistance in human multiple myeloma cells. Cancer Research 61 3071-3076.

Howlader N, Noone AM, Krapcho M, Garshell J, Miller D, Altekruse SF, Kosary CL, Yu M, Ruhl J, Tatalovich Z, et al. (eds) 2013 SEER Cancer Statistics Review, 1975-2011, National Cancer Institute. Bethesda, MD, http://seer.cancer.gov/csr/1975_2011/, based on November 2013 SEER data submission, posted to the SEER web site, April 2014

Huang R, Southall N, Wang Y, Yasgar A, Shinn P, Jadhav A, Nguyen DT \& Austin CP 2011 The NCGC pharmaceutical collection: a comprehensive resource of clinically approved drugs enabling repurposing and chemical genomics. Science Translational Medicine 3 80ps16. (doi:10.1126/scitranslmed.3001862)

Inglese J, Auld DS, Jadhav A, Johnson RL, Simeonov A, Yasgar A, Zheng W \& Austin CP 2006 Quantitative high-throughput screening: a titrationbased approach that efficiently identifies biological activities in large chemical libraries. PNAS 103 11473-11478. (doi:10.1073/pnas. 0604348103)

Jain S, Diefenbach C, Zain J \& O'Connor OA 2011 Emerging role of carfilzomib in treatment of relapsed and refractory lymphoid neoplasms and multiple myeloma. Core Evidence 6 43-57. (doi:10.2147/ CE.S13838)

Jiang Q, Li F, Shi K, Wu P, An J, Yang Y \& Xu C 2013 ATF4 activation by the p38MAPK-eIF4E axis mediates apoptosis and autophagy induced by selenite in Jurkat cells. FEBS Letters 587 2420-2429. (doi:10.1016/j. febslet.2013.06.011) 
Kebebew E, Greenspan FS, Clark OH, Woeber KA \& McMillan A 2005 Anaplastic thyroid carcinoma. Treatment outcome and prognostic factors. Cancer 103 1330-1335. (doi:10.1002/cncr.20936)

Kim JY, Nam JK, Lee SA, Lee MS, Cho SK, Park ZY, Lee JW \& Cho M 2011 Proteasome inhibition causes epithelial-mesenchymal transition upon TM4SF5 expression. Journal of Cellular Biochemistry 112 782-792. (doi:10.1002/jcb.22954)

Kudo Y, Takata T, Ogawa I, Kaneda T, Sato S, Takekoshi T, Zhao M, Miyauchi M \& Nikai H 2000 p2 $7^{\text {Kip1 }}$ accumulation by inhibition of proteasome function induces apoptosis in oral squamous cell carcinoma cells. Clinical Cancer Research 6 916-923.

Loda M, Cukor B, Tam SW, Lavin P, Fiorentino M, Draetta GF, Jessup JM \& Pagano M 1997 Increased proteasome-dependent degradation of the cyclin-dependent kinase inhibitor p27 in aggressive colorectal carcinomas. Nature Medicine 3 231-234. (doi:10.1038/nm0297-231)

Milani M, Rzymski T, Mellor HR, Pike L, Bottini A, Generali D \& Harris AL 2009 The role of ATF4 stabilization and autophagy in resistance of breast cancer cells treated with Bortezomib. Cancer Research 69 4415-4423. (doi:10.1158/0008-5472.CAN-08-2839)

Miller SC, Huang R, Sakamuru S, Shukla SJ, Attene-Ramos MS, Shinn P, Van Leer D, Leister W, Austin CP \& Xia M 2014 Identification of known drugs that act as inhibitors of NF- $\mathrm{KB}$ signaling and their mechanism of action. Biochemical Pharmacology 79 1272-1280. (doi:10.1016/j.bcp. 2009.12.021)

Mitsiades CS, McMillin D, Kotoula V, Poulaki V, McMullan C, Negri J, Fanourakis G, Tseleni-Balafouta S, Ain KB \& Mitsiades N 2006 Antitumor effects of the proteasome inhibitor bortezomib in medullary and anaplastic thyroid carcinoma cells in vitro. Journal of Clinical Endocrinology and Metabolism 91 4013-4021. (doi:10.1210/ jc.2005-2472)

Munos B 2009 Lessons from 60 years of pharmaceutical innovation. Nature Reviews. Drug Discovery 8 959-968. (doi:10.1038/nrd2961)

Nagaiah G, Hossain A, Mooney CJ, Parmentier J \& Remick SC 2011 Anaplastic thyroid cancer: a review of epidemiology, pathogenesis, and treatment. Journal of Oncology 2011 542358. (doi:10.1155/2011/ 542358)

Nilubol N, Zhang L, Shen M, Zhang YQ, He M, Austin CP \& Kebebew E 2012 Four clinically utilized drugs were identified and validated for treatment of adrenocortical cancer using quantitative high-throughput screening. Journal of Translational Medicine 10 198. (doi:10.1186/ 1479-5876-10-198)

O'Connor OA, Stewart AK, Vallone M, Molineaux CJ, Kunkel LA, Gerecitano JF \& Orlowski RZ 2009 A phase 1 dose escalation study of the safety and pharmacokinetics of the novel proteasome inhibitor carfilzomib (PR-171) in patients with hematologic malignancies. Clinical Cancer Research 15 7085-7091. (doi:10.1158/1078-0432. CCR-09-0822)

Papandreou CN, Daliani DD, Nix D, Yang H, Madden T, Wang X, Pien CS, Millikan RE, Tu SM, Pagliaro L et al. 2004 Phase I trial of the proteasome inhibitor bortezomib in patients with advanced solid tumors with observations in androgen-independent prostate cancer. Journal of Clinical Oncology 22 2108-2121. (doi:10.1200/JCO. 2004.02.106)

Parlati F, Lee SJ, Aujay M, Suzuki E, Levitsky K, Lorens JB, Micklem DR, Ruurs P, Sylvain C, Lu Y et al. 2009 Carfilzomib can induce tumor cell death through selective inhibition of the chymotrypsin-like activity of the proteasome. Blood 114 3439-3447. (doi:10.1182/blood-200905-223677)

Ruckrich T, Kraus M, Gogel J, Beck A, Ovaa H, Verdoes M, Overkleeft HS, Kalbacher H \& Driessen C 2009 Characterization of the ubiquitinproteasome system in bortezomib-adapted cells. Leukemia $\mathbf{2 3}$ 1098-1105. (doi:10.1038/leu.2009.8)

Rzymski T, Milani M, Singleton DC \& Harris AL 2009 Role of ATF4 in regulation of autophagy and resistance to drugs and hypoxia. Cell Cycle 8 3838-3847. (doi:10.4161/cc.8.23.10086)

Shahinas D, Liang M, Datti A \& Pillai DR 2010 A repurposing strategy identifies novel synergistic inhibitors of Plasmodium falciparum heat shock protein 90. Journal of Medicinal Chemistry 53 3552-3557. (doi:10.1021/jm901796s)

Shum D, Smith JL, Hirsch AJ, Bhinder B, Radu C, Stein DA, Nelson JA, Fruh K \& Djaballah H 2010 High-content assay to identify inhibitors of dengue virus infection. Assay and Drug Development Technologies 8 553-570. (doi:10.1089/adt.2010.0321)

Smallridge RC, Ain KB, Asa SL, Bible KC, Brierley JD, Burman KD, Kebebew E, Lee NY, Nikiforov YE, Rosenthal MS et al. 2012 American Thyroid Association guidelines for management of patients with anaplastic thyroid cancer. Thyroid 22 1104-1139. (doi:10.1089/thy.2012.0302)

Voorhees PM, Dees EC, O'Neil B \& Orlowski RZ 2003 The proteasome as a target for cancer therapy. Clinical Cancer Research 9 6316-6325.

Wang X, Gorospe M, Huang Y \& Holbrook NJ 1997 p2 $7^{\text {Kip1 }}$ overexpression causes apoptotic death of mammalian cells. Oncogene 15 2991-2997. (doi:10.1038/sj.onc.1201450)

Wunderlich A, Arndt T, Fischer M, Roth S, Ramaswamy A, Greene BH, Brendel C, Hinterseher U, Bartsch DK \& Hoffmann S 2012 Targeting the proteasome as a promising therapeutic strategy in thyroid cancer. Journal of Surgical Oncology 105 357-364. (doi:10.1002/jso.22113)

Yasui W, Kudo Y, Semba S, Yokozaki H \& Tahara E 1997 Reduced expression of cyclin-dependent kinase inhibitor $\mathrm{p} 27^{\mathrm{Kip} 1}$ is associated with advanced stage and invasiveness of gastric carcinomas. Japanese Journal of Cancer Research 88 625-629. (doi:10.1111/j.1349-7006.1997.tb00428.x)

Zhang L, He M, Zhang Y, Nilubol N, Shen M \& Kebebew E 2012 Quantitative high-throughput drug screening identifies novel classes of drugs with anticancer activity in thyroid cancer cells: opportunities for repurposing. Journal of Clinical Endocrinology and Metabolism 97 E319-E328. (doi:10.1210/jc.2011-2671)

Zhang L, Gaskins K, Yu Z, Xiong Y, Merino MJ \& Kebebew E 2014 An in vivo mouse model of metastatic human thyroid cancer. Thyroid 24 695-704. (doi:10.1089/thy.2013.0149)

Received in final form 6 March 2015

Accepted 20 March 2015 http://erc.endocrinology-journals.org

DOI: $10.1530 /$ ERC-14-0510
(C) 2015 Society for Endocrinology Printed in Great Britain
Published by Bioscientifica Ltd 